nais. De acordo com a literatura científica disponível este tipo de metodologia apresenta-se como uma alternativa credível, quer ao nível dos requisitos clínicos, quer ao nível de rapidez, em reabilitações orais parciais.

Descrição do caso clínico: Paciente do sexo masculino de 42 anos de idade com ausência do dente 37. História clínica sem alterações relevantes. Foram realizados ortopantomografia e CBCT (Planmeca ${ }^{\circledR}$ ), tendo sido detectadas $13 \mathrm{~mm}$ de altura e $10 \mathrm{~mm}$ de largura ósseas. Foi colocado um implante Straumann ${ }^{\circledR}$ Bone level com plataforma 4,1mm (Ref.:021.5410). Decorridos 3 meses foram realizadas impressões digitais com o scanner 3Shape (Trios ${ }^{\circledR}$, Denmark) utilizando um scan body aparafusado ao implante, criado um modelo digital. A nível laboratorial esse modelo digital foi utilizado para construir uma coroa em zircónia monolítica Prettau Zirkonzahn ${ }^{\circledR} \mathrm{com}$ interface em titânio, pelo processo de fresagem. Foi pigmentada de acordo com a cor pretendida. Posteriormente a coroa foi ajustada e aparafusada na cavidade oral do paciente.

Discussão e conclusões: A utilização desta metodologia digital permitiu: 1) Obtenção de uma boa adaptação à plataforma do implante confirmada a nível radiológico; 2) A adaptação nos contactos interproximais e na oclusão necessitou de ajustes mínimos, cumprindo deste modo os requisitos clínicos; 3) Uma melhoria de conforto ao nível do paciente, uma vez que não foram utilizados materiais passiveis de induzir reflexos de vómito; 4) Menor consumo de tempo clínico e tempo laboratorial na realização da coroa implanto-suportada. O resultado obtido coaduna-se com os resultados descritos na literatura e deste modo conclui-se que este caso pode-se considerar exemplificativo das possíveis vantagens da utilização desta técnica. Contudo convém ressalvar que a mesma requer um investimento em equipamentos considerável, devendo a sua utilização ser equacionada dentro do ambiente clinico individual.

http://doi.org/10.24873/j.rpemd.2017.12.060

\section{\#029 Frenectomia: Momento de Atuação. Descrição de Casos Clínicos}

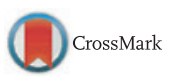

Sofia Teves Rego*, Inês Guerra Pereira, Tiago Pinto Ribeiro

Faculdade Medicina Dentária da Universidade do Porto

Introdução: O freio labial maxilar adquire particular importância pelos seus achados clínicos e radiográficos, existência de diastema mediano e não encerramento da sutura intermaxilar. Tratando-se de uma estrutura anatómica formada por finas pregas de membrana mucosa e tecido conjuntivo e que pode ter na sua constituição fibras musculares, tem como principal função limitar a mobilidade do lábio superior. Com o desenvolvimento da dentição temporária, o freio labial maxilar tende a assumir uma posição mais apical, sendo assim uma estrutura dinâmica. O diastema mediano é comum na dentição primária e mista, contudo com a erupção dos dentes definitivos, incisivos laterais e caninos maxilares permanentes, este espaço poderá encerrar-se. É importante prever se poderá existir uma autocorreção da situação, ou pelo contrário, quando e em que situação se deverá intervir cirurgicamente, realizar a frenectomia. A literatura atual ainda não permite concluir qual a melhor idade para realizar a frenectomia. Neste póster descrevem-se três casos clínicos.

Descrição dos Casos Clínicos: Serão apresentados três casos clínicos em que o momento de atuação diverge, perante condicionalismos inerentes à situação clinica do paciente. Inicialmente, é importante realizar o correto diagnóstico para a identificação do freio labial maxilar patológico através do exame clínico e imagiológico. No primeiro caso clinico a frenectomia foi realizada precocemente, em paciente com dentição mista e sem a erupção dos caninos. Os outros casos clínicos representam cirurgias efetuadas mais tarde, em que o tratamento ortodôntico estava preconizado. Pretende-se comparar a idade do paciente e cronologia de erupção, e assim explicar a realização do procedimento cirúrgico.

Discussão e conclusões: No freio labial maxilar, a frenectomia deve ser realizada após a erupção dos caninos maxilares permanentes. No entanto, quando o diastema é amplo, este procedimento necessita ser realizado precocemente para permitir o encerramento do diastema. Em dentição decídua esta cirurgia não é recomendada. Quando existe persistência do diastema, após a erupção dos caninos permanentes maxilares, a frenectomia deve ser associada ao tratamento ortodôntico, depois da colocação do aparelho fixo ou pouco tempo antes da sua remoção.

http://doi.org/10.24873/j.rpemd.2017.12.061

\section{\#030 Reabilitação oral de caso clínico com comunicação oro-antral após carcinoma do zigomático}

Lurdes Veloso*, Luís Alves, Nuno Sampaio, Avelino Santos, David Sanz, Pedro Nicolau

Cirurgia Maxilo-Facial do Centro Hospitalar e Universitário de Coimbra, Área de Medicina Dentária da Faculdade de Medicina da Universidade de Coimbra

Introdução: O tratamento cirúrgico para a ablação de tumores malignos na maxila pode resultar em comunicações oro-antrais severas, resultando numa diminuição da capacidade de fonação e mastigação, comprometendo também a estética. Na maioria dos casos, as próteses obturadoras conferem ao paciente uma melhoria da qualidade de vida e da sua auto-estima.

Descrição do caso clínico: Uma paciente do sexo feminino, de 66 anos, com uma desdentação parcial extensa resultante da cirurgia maxilo-facial após um carcinoma do osso zigomático, em 2013, recorreu à clínica da pós-graduação em reabilitação oral protética da FMUC em 2015, sem qualquer tipo de reabilitação protética. Apresentava um defeito unilateral, afetando o palato duro e mole e uma comunicação com a cavidade nasal, acompanhada de limitação da abertura bucal, por anquilose fibrótica da articulação temporomandibular (ATM). O principal objetivo da paciente era a reposição da função e eficácia mastigatória. Devido à limitação da amplitude de abertura bucal, foi necessário recorrer a cirurgia da ATM, resultando num aumento de amplitude de 20 para $34 \mathrm{~mm}$. Dada a extensão do defeito e ao risco de introduzir material de impressão na comunicação, foi decidido utilizar uma a técnica 